\title{
Beyond dynamical mean-field theory of neural networks
}

\author{
Massimiliano Muratori", Bruno Cessac \\ From Twenty Second Annual Computational Neuroscience Meeting: CNS*2013 \\ Paris, France. 13-18 July 2013
}

We consider a set of $\mathrm{N}$ firing rate neurons with discrete time dynamics and a leak term $\gamma$. The nonlinearity of the sigmoid is controlled by a parameter $g$ and each neuron has a firing threshold $\theta$, Gaussian distributed (thresholds are uncorrelated). The network is fully connected with correlated Gaussian random synaptic weights, with mean zero and covariance matrix $\mathrm{C} / \mathrm{N}$. When synaptic weights are uncorrelated the dynamic mean field theory developed in [1-3] allows us to draw the bifurcation diagram of the model in the thermodynamic limit ( $\mathrm{N}$ tending to infinity): in particular there is sharp transition from fixed point to chaos characterized by the maximum Lyapunov exponent, which is known analytically in the thermodynamic limit. The bifurcation diagram is drawn in Figure 1 A. However, mean-field theory is exact only in the thermodynamic limit and when synaptic weights are uncorrelated. What are the deviations from mean-field theory observed when one departs from these hypotheses? We have first studied the finite size dynamics. For finite $\mathrm{N}$ the maximal Lyapunov exponent has a plateau at 0 corresponding to a transition to chaos by quasi-periodicity where dynamics is at the edge of chaos (Figure $1 \mathrm{~B}$ ). This plateau disappears in the

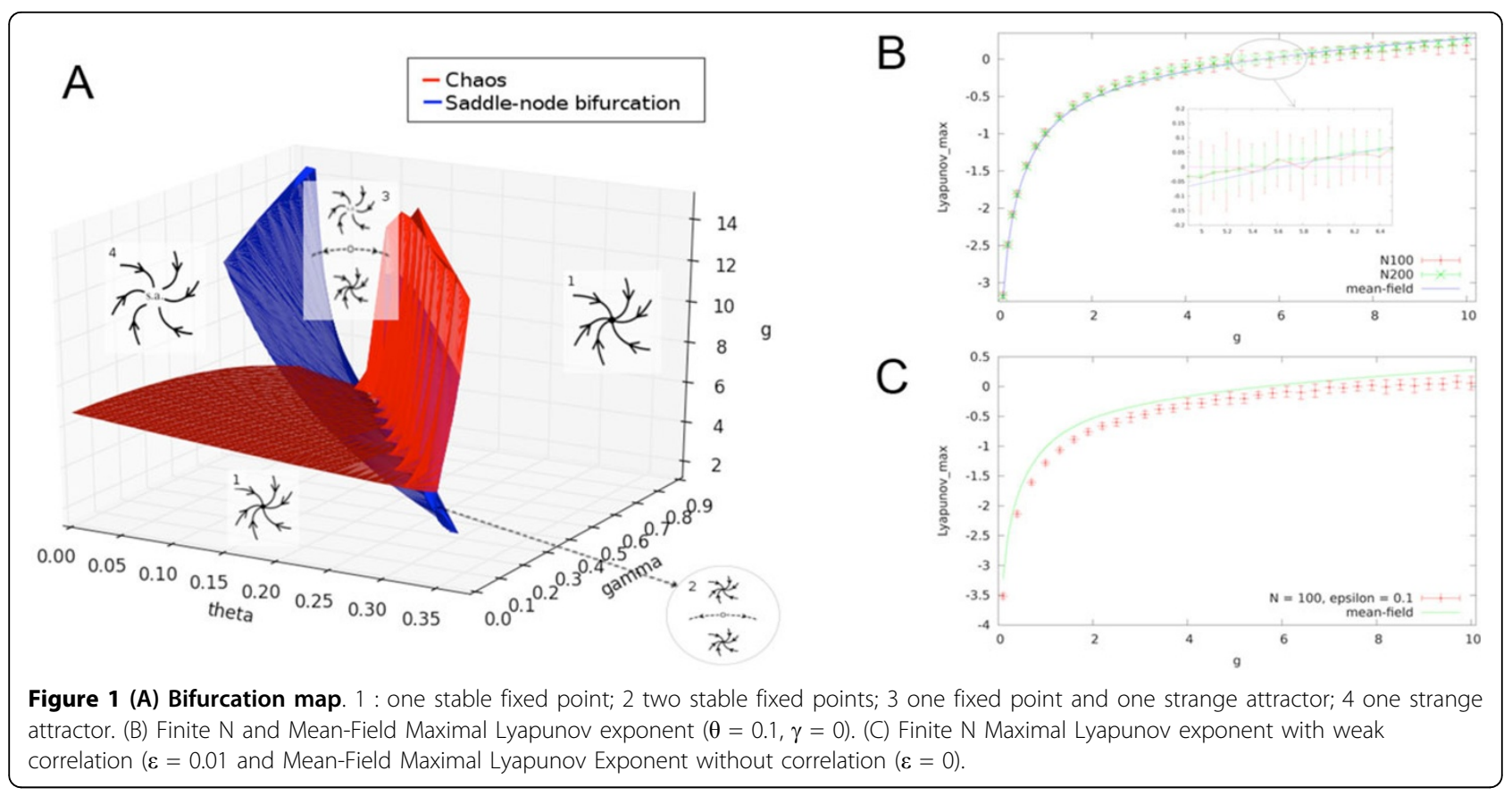

NeuroMathComp team (INRIA, UNSA LAD), Sophia Antipolis, France 
thermodynamic limit. Thus, mean-field theory neglects an important finite-sized effect since neuronal dynamics at the edge of chaos has strong implications on learning performances of the network [4]. We also studied the effect of a weak correlation (of amplitude $\varepsilon$ ) on dynamics. Even, when $\varepsilon$ is small one detects an important deviation on the maximal Lyapunov exponent (Figure $1 \mathrm{C}$ ).

\section{Acknowledgements}

This work was supported by INRIA, ERC-NERVI number 227747, KEOPS ANRCONICYT and European Union Project \# FP7-269921 (BrainScales), Renvision grant agreement N 600847 and Mathemacs FP7-ICT_2011.9.7.

Published: 8 July 2013

\section{References}

1. Cessac B, Doyon B, Quoy M, Samuelides M: Mean-field equations, bifurcation map and route to chaos in discrete time neural networks. Physica D 1994, 74:24-44

2. Cessac B: Increase in Complexity in Random Neural Networks. J Phys I France 1995, 5:409-432.

3. Moynot O, Samuelides M: Large deviations and mean-field theory for asymmetric random recurrent neural networks. Probability Theory and Related Fields 2002, 123:41-75, Springer-Verlag.

4. Legenstein R, Maass W: Edge of Chaos and Prediction of Computational Performance for Neural Circuit Models. Neural Networks 2007, 20:323-334.

doi:10.1186/1471-2202-14-S1-P60

Cite this article as: Muratori and Cessac: Beyond dynamical mean-field theory of neural networks. BMC Neuroscience 2013 14(Suppl 1):P60.

\section{Submit your next manuscript to BioMed Central} and take full advantage of:

- Convenient online submission

- Thorough peer review

- No space constraints or color figure charges

- Immediate publication on acceptance

- Inclusion in PubMed, CAS, Scopus and Google Scholar

- Research which is freely available for redistribution

Submit your manuscript at www.biomedcentral.com/submit
C Biomed Central 